\title{
Guilt Enhances the Sense of Control and Drives Risky Judgments
}

\section{Citation}

Kouchaki, M., C. Oveis, and F. Gino. "Guilt Enhances the Sense of Control and Drives Risky Judgments." Journal of Experimental Psychology: General (in press).

\section{Published Version}

doi:10.1037/a0037932

\section{Permanent link}

http://nrs.harvard.edu/urn-3:HUL.InstRepos:13244608

\section{Terms of Use}

This article was downloaded from Harvard University's DASH repository, and is made available under the terms and conditions applicable to Open Access Policy Articles, as set forth at http:// nrs.harvard.edu/urn-3:HUL.InstRepos:dash.current.terms-of-use\#OAP

\section{Share Your Story}

The Harvard community has made this article openly available.

Please share how this access benefits you. Submit a story.

Accessibility 
Guilt Enhances the Sense of Control and Drives Risky Judgments

\author{
Maryam Kouchaki \\ Northwestern University
}

Christopher Oveis

Rady School of Management

Francesca Gino

Harvard University

In press, Journal of Experimental Psychology: General 
Words: 5,789 


\begin{abstract}
The present studies investigate the hypothesis that guilt influences risk-taking by enhancing one's sense of control. Across multiple inductions of guilt, we demonstrate that experimentally induced guilt enhances optimism about risks for the self (Study 1), preferences for gambles versus guaranteed payoffs (Studies 2, 4, and 6), and the likelihood that one will engage in risktaking behaviors (Study 5). In addition, we demonstrate that guilt enhances the sense of control over uncontrollable events, an illusory control (Studies 3, 4, and 5), and found that a model with illusory control as a mediator is consistent with the data (Studies 5 and 6). We also found that a model with feelings of guilt as a mediator, but not generalized negative affect, fits the data (Study 4). Finally, we examined the relative explanatory power of different appraisals and found that appraisals of illusory control best explain the influence of guilt on risk-taking (Study 6). These results provide the first empirical demonstration of the influence of guilt on sense of control and risk-taking, extend previous theorizing on guilt, and more generally contribute to our understanding of how specific emotions influence cognition and behavior.
\end{abstract}


The experience of guilt brings the self into sharp negative focus, but ironically promotes productive behavior in its aftermath: when individuals feel guilty, they are motivated to act (e.g., Lewis, 1971). Realizing that they have failed to live up to their standards, people attempt to undo their actions, repair their relationships, and bring future actions in line with their morals (e.g., Tangney \& Dearing, 2002). In this paper, we identify another behavioral consequence of feeling guilty: an enhanced tendency to take risks.

Specifically, we pursue three aims relevant to guilt and risk. First, we examine how the experience of guilt influences risk-related judgments, including optimism about future risks, the preference for gambles over guaranteed payoffs, and perceptions of the likelihood of engaging in future risks, which correlate with real-world risk-taking behaviors (Hanoch, Johnson, \& Wilke, 2006). Second, we investigate a potential mechanism of the influence of guilt on risk: an illusory sense of control. To do so, we examine how the experience of guilt enhances perceived control over uncontrollable outcomes and whether an enhanced sense of control can explain the influence of guilt on risk-taking judgments.

\section{An Appraisal Tendency Account of Emotional Influences on Risk-taking}

In this paper, we take an appraisal tendency approach to the influence of emotion on risktaking (Han, Lerner, \& Keltner, 2007; Horberg, Oveis, \& Keltner, 2011; Lerner \& Keltner, 2000, 2001; Siemer, 2001). This theory presumes that specific emotions both arise from and leave behind particular sets of enhanced cognitive appraisals. The experience of a specific emotion, then, creates a tendency to view subsequent events through the lens of that particular emotion's associated appraisals, thus impacting relevant judgments and behaviors. Several studies have contrasted the emotion-specific appraisal tendency effects of anger and fear in the domain of risk. Anger and fear are both negative emotions, but anger is associated with appraisals of 
personal control and certainty whereas fear is associated with appraisals of situational control and uncertainty (Smith \& Ellsworth, 1985). Consistent with this appraisal analysis, trait fear is associated with decreased and trait anger with increased estimates of the occurrence of risky events (Lerner \& Keltner, 2000), optimism about whether risky events will happen to the self (Lerner \& Keltner, 2001), and preference for gambles versus "sure thing" options in the Asian Disease problem (Lerner \& Keltner, 2001). Likewise, induced fear decreases and anger increases optimism about whether risky events will happen to the self, and appraisals of control mediate these judgments (Lerner \& Keltner, 2001).

These results dovetail with work from decision science demonstrating that appraisals of certainty and control are the two central dimensions governing decisions about risk. To the extent that the consequences of an activity are viewed as uncertain ("unknown risk") and uncontrollable ("dread risk"), that activity is perceived to be more risky (Slovic, 1987). It is interesting to note that the control appraisal factor, rather than the certainty appraisal factor, is the critical one in influencing individuals' desire to avoid or reduce the risks of a particular activity (Slovic, 1987). In addition, individuals who perceive high personal control over their environment are more likely to engage in risk-taking behavior (Scheier, Carver, \& Bridges, 1994). Thus, we propose that other emotions associated with an enhanced or diminished sense of control are likely to influence risk perceptions and risk-taking behavior. Guilt is one such emotion; guilt is defined by appraisals of personal control but is not centrally defined by appraisals of certainty (Smith \& Ellsworth, 1985; Tracy \& Robins, 2006). Here, we investigate whether guilt diminishes perceptions of risk and promotes risk-taking behavior.

\section{Guilt, Risk-taking, and Control}

Guilt, an emotion experienced when an individual's behavior fails to meet their standards 
(Lazarus, 1991; Tangney \& Dearing, 2002), plays an important role in driving behavior. The feeling of guilt is produced when "individuals evaluate their behavior as failure but focus on specific features or actions of the self that led to the failure" (Lewis, 2008: 748). The feeling is directed to the cause of failure, rather than self; as a result, guilt leads to corrective action to repair failure (Lewis, 1971). Guilt weighs heavily on the psyche; when individuals experience guilt, they become motivated to change their circumstances, to alleviate their feelings of guilt, and more generally to take action (Lindsay-Hartz, 1984). Guilt also plays a critical role in promoting prosocial, moral behavior (Baumeister, Stillwell, \& Heatherton, 1994; Izard, 1977; Tangney \& Dearing, 2002).

In this paper, we argue that guilt promotes risk-taking. Intuitively, however, the opposite proposition — that guilt should lead to less risky behavior - may seem more likely. Indeed, some research shows that guilt proneness is inversely related to risky behavior. For instance, guiltprone college students are less likely to abuse drugs and alcohol (Dearing, Stuewig, \& Tangney, 2005). However, guilt proneness is characterized by the anticipation of feeling bad, not guilty, after an eliciting event. The argument supporting this claim builds on the idea that, as an uncomfortable emotion, guilt drives less risky behavior to avoid experiencing further guilt or other negative emotions associated with failure. Here, we test the idea that guilt instead increases optimism and preferences for risk as well as the likelihood of risk-taking behavior. This should occur, we reason, because guilt enhances perceived control over one's environment. Individuals appraise guilt-inducing events with attributions of self-responsibility for failure, and enhanced appraisals that events are controllable (Tracy \& Robins, 2006), a feature shared by positive emotions such as joy and happiness, and by the negative emotion anger (Frijda, Kuipers, \& ter Schure, 1989; Lerner \& Keltner, 2001; Smith \& Ellsworth, 1985). Although guilt belongs to the 
class of emotions featuring a negative self-evaluation (Ortony, Clore, \& Collins, 1988), such that one's actions are appraised negatively, the appraisal process signals that one was in control of doing something wrong (i.e., responsible for it); thus, the experience of guilt results in action tendencies to correct the wrongdoing and make reparations to those harmed (Frijda et al., 1989; Lewis, 1971). Guilt implies that the self is able to act to restore moral order (Lewis, 1971). A causal effect of control beliefs on guilt has been documented previously (Berndsen \& Manstead, 2007), but, no study has yet demonstrated that guilt increases sense of control.

In a set of studies, Lindsay-Hartz and colleagues found that participants providing guilt descriptions used the terms, "I could" and "I could have" frequently and were convinced that they had some control over the situation (Lindsay-Hartz, 1984; Lindsay-Hartz, Rivera, Mascolo, 1995). Sense of control (or agency) and taking action are highly interrelated (Haggard \& Tsakiris, 2009); if individuals think they do not have any control, they lose their motivation to act (Skinner, 1996). On the other hand, performing an action makes people feel a sense of control. Even the mere prime of potential action before an action itself is performed enhances feelings of control (Aarts, Custers, \& Wegner, 2005) over objectively uncontrollable stimuli (Linser \& Goschke, 2007). Taken together, these studies suggest that guilt should be strongly related to perceived personal control, but yet this relationship has not been assessed directly.

If guilt promotes a sense of control, then it follows that feeling guilt may actually promote risk-taking and more optimistic perceptions of future risk. Following work demonstrating incidental influences of emotion upon cognition (e.g., Clore \& Huntsinger, 2007; Keltner, Horberg, \& Oveis, 2006; Schwarz \& Clore, 1983), we propose that guilt-driven risky tendencies should extend to judgments of risks that are irrelevant to the guilt-eliciting situation. We further argue that guilt should produce an illusion of control such that individuals feel 
personal control in objectively uncontrollable or chance-determined situations (Langer, 1975). Thus, in addition to testing the effects of guilt on perceived control and risk-taking, we examine whether our data are consistent with a model in which illusory control serves as mediator of the relationship between guilt and risk-taking.

We conducted six studies to examine our predictions that guilt (a) promotes optimistic perceptions regarding risk, (b) increases preference for risks, and beliefs that one will engage in risk-taking behavior, and (c) increases perceived control over uncontrollable events. In Studies 5 and 6, we tested whether our data is consistent with a model in which a guilt-induced sense of control mediates the effect of guilt on increased risk-taking tendencies. Additionally, in Study 6 we assessed different appraisals associated with guilt and examined the effects of these specific appraisals on risk-taking in addition to guilt-induced illusory sense of control.

\section{Study 1: Guilt Enhances Optimistic Risk Estimates}

In Study 1, we examined whether induced guilt would produce more optimistic risk estimates compared to a neutral control condition as well as to sadness, a negatively-valenced control emotion. Following the appraisal tendency framework (Lerner \& Keltner, 2001), we selected sadness as a comparison emotion because it shares a negative valence with guilt and similarly involves negative appraisals of events, but differs on the appraisal of interest: controllability. Whereas guilt involves appraisals of one's own control over an event, sadness is associated with appraisals of the uncontrollability of an event (Frijda et al., 1989). We also included a neutral control condition to demonstrate that guilt increases risk optimism as compared to a neutral baseline. Following Lerner and Keltner (2001), we measured optimistic risk by asking participants to estimate the likelihood that specific positive and negative events would occur in their lives. We predicted that the experience of guilt would increase optimistic 
risk estimates relative to sadness and the neutral control.

\section{Method}

Seventy-four students ( 45 males; $M_{a g e}=23.9$ years, $S D=4.3$ ) at a university in the western United States were randomly assigned to one of three emotion conditions (neutral, guilt, sadness). Following Tangney and colleagues (1996), participants in the guilt condition received the following instructions:

Please recall a time in your personal life where you behaved in a way that made you feel guilt. Please describe the details about this situation that made you feel guilty. What was it like to be in this situation? What thoughts and feelings did you experience? Describe the situation and any thoughts, feelings you experienced. Please provide as many details as possible so that a person reading your entry would understand the situation and how you felt.

Participants in the neutral condition were asked to describe a typical afternoon in writing. In the sadness condition, using instructions similar to the guilt condition, participants recalled a time in their personal lives where they behaved in a way that made them feel sad.

After the written narrative, respondents completed the 6-item optimistic risk estimates scale from the Life Events Questionnaire (Winterich, Han, \& Lerner, 2010; adapted from Lerner \& Keltner, 2001) using a 7-point scale (1=very unlikely, $7=$ very likely). Sample items in this scale are "I could not find a job for six months" (reverse-coded) and "I had a heart attack before age 50" (reverse-coded). Items were averaged to form an optimistic risk estimates score $(\alpha=.75)$.

\section{Results}

As predicted, the manipulation affected participants' risk estimates, $F(2,71)=4.75, p=.01$, partial $\eta^{2}=.12$. Pairwise comparisons indicated that risk estimates were significantly more 
optimistic in the guilt condition $(M=5.16, S D=.59)$ than in the sadness condition $(M=4.47$, $S D=.95 ; t(48)=3.05, p=.003, d=.87)$ and were marginally higher as compared to the neutral condition $(M=4.76, S D=.78 ; t(46)=1.98, p=.05, d=.58)$. The sadness and neutral conditions did not significantly differ in their influence on optimistic risk estimates.

\section{Study 2: Guilt Enhances Risk Preferences}

Study 1 demonstrated that incidental guilt influences the perception of risk. In Study 2, we examined whether guilt influences the preference for risks versus guaranteed payoffs. We predicted that the experience of guilt would increase risk preference relative to a neutral control. To further examine the generalizability of the influence of guilt on risk preferences, we used a different manipulation of guilt.

\section{Method}

Eighty-five individuals (40 males, $M_{a g e}=31.7$ years, $S D=9.0$ ) recruited through MTurk (\$1 payment) were randomly assigned to one of two emotion conditions (neutral, guilt). Following De Hooge and colleagues (2011), we induced guilt or a neutral state using the following computer task. Participants were informed that as part of a study on perceptions and reaction times, they would play two rounds of a performance task (ostensibly) with a partner; the combined performance of both partners could earn the pair $\$ .50$ each. In the first round, the performance bonus would be earned by the participant; in the second round, the performance bonus would be earned by their ostensible partner. (No participant reported suspicion that their counterpart was not real.)

The partners then played a word game, Boggle, in which they were given a grid of letters and were asked to find words in sequences of adjacent letters in 30 seconds. Importantly, both partners needed to do well in order to reach the minimum level of points to get the bonus. After 
the first round, participants received feedback that they earned the bonus because of the good performance of both partners. After the second round, participants in the guilt condition were informed that the pair together earned less than the threshold of 100 points and thus their partner missed out on the bonus, whereas participants in the neutral condition were informed that their partner received the bonus because of both partners' good performance.

Next, to assess risk preferences, participants made four dichotomous choices for the following question: "Do you want a 50\% chance of getting \$800 OR \$ for sure?"

(Griskevicius, Tybur, Delton, \& Robertson, 2011). The amount ranged systematically from $\$ 100$ to $\$ 400$ in $\$ 100$ increments. The dependent measure consisted of the total number of risky options chosen by a participant (0-4). As an emotion manipulation check, similar to De Hooge et al. (2011), participants then rated on 7-point scales (1=not at all, 7=very much) how much guilt, shame, regret, disappointment, sadness, fear, and anger they felt after receiving the perception task feedback.

\section{Results}

Participants in the guilt condition reported greater guilt $(M=3.98, S D=1.91)$ than did those in the neutral condition $(M=1.45, S D=1.02), t(83)=7.58, p<.001, d=1.65$, indicating that the manipulation was successful. In addition, participants in the guilt condition reported significantly greater guilt than other emotions, all $t \mathrm{~s}(42)>4.10, p \mathrm{~s}<.01$.

We expected that guilt would lead participants to exhibit a greater preference for risks. Consistent with this prediction, participants in the guilt condition preferred greater risks $(M=1.35, S D=1.36)$ than did those in the neutral condition $(M=.76, S D=1.27), t(83)=2.06, p=.04$, $d=.45$.

\section{Study 3: Guilt Increases the Sense of Control}


Study 2 provided evidence that guilt increases the preference for risks. In Study 3, we examined our prediction that guilt increases illusions of control such that individuals feel personal control in objectively uncontrollable situations. Here, we used a different manipulation of guilt, asking participants to put themselves in the shoes of a person experiencing guilt.

\section{Method}

One hundred-fifty MTurk participants (91 males, $M_{a g e}=27.9$ years, $S D=7.8 ; \$ 1$ compensation) were randomly assigned to experience guilt or a neutral state. All participants imagined being in a hurry because they wanted to get a special offer at a shop just before closing time (De Hooge et al., 2011). They were told that because they did not have any means of transportation, they had borrowed a friend's bicycle, which was very special to him. In the guilt condition, participants were informed that when they left the shop, they found that the bicycle, which they forgot to lock, had been stolen. The story continued by telling participants that when they informed their friend about the stolen bike, he was very sad. In the neutral condition, participants returned the bicycle to their friend without incident.

Next, participants completed an illusion of control measure (Fast, Gruenfeld, Sivanathan, \& Galinsky, 2009) by indicating their perceived control over four hard-to-control outcomes (e.g., "To what extent are you able to have some control over what happens in the economy?" $\alpha=.86$ ) on 7-point scales $(1=$ very little control, $7=$ a great deal of control). Participants then rated the emotion questions of Study 2 referring to how they felt at the end of the story on 7-point scales (1=not at all, 7=very much). Participants also completed the PANAS (Watson et al., 1988), reporting how they felt at the end of the story on 5-point scales (1=very slightly or not at all, $5=$ extremely).

\section{Results}


The guilt condition $(M=6.32, S D=1.36)$ produced more feelings of guilt than did the neutral condition $(M=2.49, S D=1.66), t(148)=15.48, p<.001, d=2.52$, indicating that the manipulation of guilt was successful. Compared to participants in the neutral condition, those in the guilt condition reported more negative affect $\left(M_{\text {guilt }}=2.64\right.$ vs. $M_{\text {neutral }}=1.28, t(148)=10.85$, $p<.001, d=1.77)$ and less positive affect $\left(M_{\text {guilt }}=1.98\right.$ vs. $M_{\text {neutral }}=2.51, t(148)=3.68, p<.001$, $d=.60)$. Moreover, participants in the guilt condition reported experiencing significantly more guilt than other emotions, all $t \mathrm{~s}(74)>2.26, p \mathrm{~s}<.05$.

As predicted, participants in the guilt condition felt a greater sense of control $(M=2.62$, $S D=1.25)$ than did those in neutral condition $(M=2.10, S D=1.04), t(148)=2.79, p=.006, d=.45$.

\section{Study 4: Feelings of Guilt Increase Risk Preferences}

To add confidence to the assertion that feelings of guilt, rather than some other aspect of our manipulation, influence risk preferences, we tested whether a model with participants' feelings of guilt as a mediator is consistent with the data to explain the influence of the guilt induction on an increased preference for risk. Moreover, consistent with Lerner and Keltner's (2001) findings that negative affect does not account for emotion-specific risk effects, we used mediation analyses to test whether negative affect might explain the influence of guilt on risk preferences.

\section{Method}

Seventy students ( 44 males; $M_{\text {age }}=24.5$ years, $S D=5.7$ ) at a university in the western United States were randomly assigned to one of two emotion conditions (neutral, guilt), manipulated using a writing task as in Study 1. After the emotion induction, participants answered a few filler items. Next, we assessed risk preferences using the Griskevicius et al. (2011) gambling vs. sure thing choice task employed in Study 2. Finally, participants completed 
the PANAS (Watson et al., 1988) and the state guilt items from the PANAS-X (Watson \& Clark, 1994; "guilty," "blameworthy," "angry at self"; $\alpha=.90)$. For the above emotion items, participants reported how they felt during the emotion induction by rating each item on a 5-point scale (1=very slightly or not at all; 5=extremely).

\section{Results}

Participants in the guilt condition reported greater guilt $(M=1.67, S D=.76)$ than did those in the control condition $(M=1.20, S D=.24), t(68)=3.56, p=.001, d=.83$, indicating that the manipulation was successful. In addition, participants in the guilt condition reported greater negative affect $(M=1.82, S D=.63)$ than did those in the control condition $(M=1.41, S D=.42)$, $p=.002, d=.83$. But the guilt condition did not have a significant effect on positive affect $\left(M_{\text {guilt }}=2.82\right.$ vs. $\left.M_{\text {neutral }}=2.80, p=.93\right)$.

Consistent with our predictions, participants in the guilt condition preferred greater risks $(M=2.22, S D=1.22)$ as compared to those in the neutral condition $(M=1.41, S D=1.37)$, $t(68)=2.61, p=.01, d=.62$.

We found that a model with feelings of guilt as a mediator fit our data explains the influence of guilt on risk preferences (Preacher \& Hayes, 2004). The emotion condition had a statistically significant effect on feelings of guilt $(b=.48, S E=.14, p<.001)$, which, in turn, significantly affected risk preference $(b=.60, S E=.27, p=.03)$. The effect of our guilt manipulation was reduced (from $b=.81, S E=.31, p=.01$ to $b=.52, p=.11$ ) when feelings of guilt were included in the equation, and a bootstrap analysis (with 5,000 iterations) showed that the 95\% bias-corrected confidence interval for the size of the indirect effect excluded zero [.053, $.590]$. Our data did not support negative affect as a potential mediator of the effect of the guilt condition on risk preference; the $95 \%$ bias-corrected confidence interval for the size of the 
indirect effect included zero [-.129, .351].

\section{Study 5: The Role of Sense of Control in Explaining the Influence of Guilt on Risk-taking}

In Study 5, we tested whether our data is consistent with a model in which illusion of control mediates the relationship between guilt and risky behavior.

\section{Method}

Eighty-eight students ( 52 males, $M_{a g e}=24.1$ years, $S D=5.9$ ) at a university in the western United States were randomly assigned to one of two emotion conditions (neutral, guilt) using an emotion induction similar to that employed in Study 2 (here, lottery tickets were used as a bonus, and a red/green letter perception task was used instead of Boggle). Participants then completed measures of illusion of control and likelihood of engaging in risky behaviors. As in Study 2, we measured illusion of control $(\alpha=.92)$ by asking participants about their ability to control four hard-to-control outcomes. We assessed participants' likelihood of engaging in risk-taking behaviors $(\alpha=.76)$ using the three items of financial gambling from the domain-specific risktaking scale (DOSPERT; Blais \& Weber, 2006), on a 7-point scale (1=extremely unlikely, 7=extremely likely). A sample item is “Betting a day's income on the outcome of a sporting event." As a manipulation check, participants rated how they felt after receiving the task feedback on the emotion-manipulation check items of Study 2 using 11-point scales $(0=$ not at all, 10=very strongly).

\section{Results}

Participants in the guilt condition $(M=6.16, S D=3.05)$ reported more feelings of guilt than did those in the neutral condition $(M=1.70, S D=2.49), t(86)=7.50, p<.001, d=1.60$, indicating that the manipulation of guilt was successful. Moreover, those in the guilt condition reported feeling significantly more guilt than other emotions, all $t \mathrm{~s}(43)>2.00, p \mathrm{~s}<.05$. 
As predicted, participants in the guilt condition indicated a greater likelihood to take risks $(M=2.45, S D=1.08)$ than did those in neutral condition, $(M=1.73, S D=1.61), t(86)=-2.44, p=.02$, $d=.53$, and they also felt a greater sense of control $\left(M_{\text {guilt }}=3.34, S D=1.43\right.$ vs. $M_{\text {neutral }}=2.57$, $S D=1.32), t(86)=-2.56, p=.01, d=.60$.

A model with illusion of control as a mediator was consistent with our data (Preacher \& Hayes, 2004). The emotion condition had a statistically significant effect on sense of control $(b=.76, S E=.29, p=.01)$, which, in turn, significantly affected risk-taking $(b=.24, S E=.10, p=.02)$. The effect of the emotion manipulation on risk-taking was significantly reduced (from $b=.71$, $S E=.30, p=.017$ to $b=.53, S E=.30, p=.08$ ) when illusion of control was included in the equation, and a bootstrap analysis (with 5,000 iterations) showed that the 95\% bias-corrected confidence interval for the size of the indirect effect excluded zero $[.010, .498]$.

\section{Study 6: Guilt Appraisals}

Study 5 demonstrated that a model in which illusion of control serves as mediator for the relationship between guilt and risk-taking is consistent with our data. However, this does not rule out that other appraisals may better account for the influence of guilt on risk-taking. As noted earlier, guilt shares appraisals with negative emotions as well as with positive emotions. In Study 6, we relied on prior literature (e.g., Ellworth \& Scherer, 2003; Lazarus, 1991; Roseman et al., 1990; Smith \& Ellsworth, 1985) to identify a host of appraisals associated with guilt. Here, we once again examined the influence of guilt on risk-taking, and then simultaneously tested several appraisals as potential mediators.

\section{Method}

One hundred forty mTurk participants (68 males, $M_{a g e}=31.9$ years, $S D=8.5 ; \$ 1$ payment) were randomly assigned to receive the writing task induction of neutral or guilt from Study 1. 
Next, we assessed risk preferences using the Griskevicius et al. (2011) gambling vs. sure thing choice task employed in Study 2. Then, we measured the following appraisals in randomized order using 1 (not at all) to 7 (very much) scales (except where noted), beginning with the stem "In the events I described in the recall task...":

Illusory control. We assessed illusion of control using the three items from Study 3 (Fast et al., 2009; alpha=.86).

Control. We assessed control appraisals using the following three items (Lerner \& Keltner, 2001): “To what extent did you feel that someone other than yourself had the ability to influence what was happening?"; "To what extent did you feel that someone else was to blame for what was happening?"; and "To what extent were the events beyond anyone's control?" $(\mathrm{alpha}=.64)$ Appraisal of control helps us to examine whether illusion per se is important or not.

Uncertainty. Uncertainty appraisals were assessed using three items (Smith \& Ellsworth, 1985): "How well did you understand what was happening in the situation? (reverse-scored)"; “How well could you predict what was going to happen next?" (reverse-scored); and "How uncertain were you about what would happen in other situations?” (alpha=.62)

Self-responsibility. Self-responsibility appraisals were assessed using three items: "How responsible did you feel for having brought about the events that you described in the recall task?";"How responsible did you think someone or something other than yourself was for having brought about the events that you described in the recall task?” (reverse-scored; Smith \& Ellsworth, 1985); and "Do you think that the cause of the events you described is due to something about you or to something about other people or circumstances?" $(1=$ completely due to other people or circumstances; 7=completely due to me; Tracy \& Robins, 2006; alpha=.69).

Pleasantness. Pleasantness appraisals were assessed using two items (Smith \& Ellsworth, 
1985): "How pleasant or unpleasant was it to be in this situation?"; and "How enjoyable was it to be in this situation?" (alpha=.90)

Social-exchange. Emotions differ in assessment of the level of exchanges in a relationship, what someone does for others and what others do for them. Guilty people may feel that they have exploited somebody else or feel an obligation to repay another because of what they have done. Social-exchange appraisals were assessed using two items: "I felt a desire to repay the person/people I wronged"; and "I felt like I owed the person/people I wronged a debt" (alpha=.97).

Assimilation/accommodation. Certain emotions promote the tendency to adapt one's behavior to environmental demands (accommodation), whereas other emotions promote the tendency to behave according to internal traits and impulses (assimilation; Bless \& Fiedler, 2006; Fiedler, 2001; see also Galinsky et al., 2008). Assimilation/accommodation appraisals were assessed using four items: "I was motivated to act to change the situation"; "I wanted to go against an obstacle or difficulty, or to conquer it"; "I felt that my actions should be influenced by the goals of others and/or by social norms" (reverse-scored); and "I felt that my behavior should be guided by my own goals and not by the goals of others" (alpha=.58)

Approach/avoidance. Approach/avoidance appraisals were assessed using three items (Roseman et al., 1990): "At the time, were you reacting to the events you described mostly because you wanted to get or keep something pleasurable, or mostly because you wanted to get rid of or avoid something painful?" (1=mostly because I wanted to get or keep something pleasurable; 7=mostly because I wanted to get rid of or avoid something painful; reversescored); "Did you want to minimize some cost in the events you described or maximize some benefit?" (1=very much wanted to minimize some cost; 7=very much wanted to maximize some 
benefit); and "Were you seeking less of something negative, or more of something positive?" (1=very much seeking less of something negative; $7=$ very much seeking more of something positive; alpha=.78).

\section{Results}

Four participants did not complete the writing task and were excluded from analyses. Consistent with our previous studies, participants in the guilt condition reported significantly greater likelihood to take risks $(M=1.63, S D=1.29)$ than did those in neutral condition $(M=1.04$, $S D=1.91), t(134)=-2.76, p=.007, d=.36$, and they also showed higher mean levels of illusion of control that did not reach conventional levels of significance $\left(M_{\text {guilt }}=2.28, S D=1.09\right.$ vs. $\left.M_{\text {neutral }}=1.98, S D=1.19\right), t(134)=-1.55, p=.12, d=.26$. Descriptive statistics and correlations among the study variables are presented in Table 1.

Three appraisals were significantly (illusion of control, $r=.20, p=.02$; uncertainty, $r=.19$, $p=.03$ ) or marginally (control, $r=.15, p=.08$ ) associated with risk-taking. To examine which appraisal best explained the influence of guilt on risk-taking, we used multiple mediation analysis (i.e., simultaneous mediation by multiple variables) with all the measured appraisals. Results with 5,000 bootstrap samples provided marginally significant support for a model in which illusion of control serves as mediator for the relationship between guilt and risk-taking; the $90 \%$ bias-corrected confidence interval for the indirect effect did not include zero (.002, .202). In this simultaneous mediation model, no other appraisal reached marginal levels of significance as a potential mediator. In sum, among the appraisals that we tested, illusion of control best explains the effect of guilt on risk-taking.

\section{General Discussion}

Guilt is a powerful driver of behavior. The present studies demonstrate that feelings of 
guilt promote risk-taking. Across six studies, using behavioral and priming manipulations of guilt, we showed that guilt led to more optimistic risk perceptions (i.e., decreased risk estimates) (Study 1), preference for risky gambles versus guaranteed payoffs (Studies 2, 4, and 6), and the likelihood of engaging in risk-taking behaviors (Study 5). Consistent with appraisal analyses of guilt, we empirically demonstrated for the first time that guilt increases illusions of control over uncontrollable outcomes (Studies 3, 4, and 5). Additionally, we tested and found support for a model of the influence of guilt on increased risk-taking through enhanced illusory control (Studies 5 and 6). Finally, we examined different appraisals associated with guilt and the effects of these specific appraisals on risk-taking.

Together, these results suggest that guilt can have important effects on individuals' perceptions and behaviors related to risk. Importantly, all of the studies presented in this paper demonstrated incidental effects of guilt; that is, feelings of guilt generated by one cause impacted judgments that were completely irrelevant to the original cause of guilt. While we believe it is likely that feelings of guilt will also increase risk-taking for the purpose of atoning for one's guilt-inducing behavior (i.e., integral emotion effects; e.g., Han, Lerner, \& Keltner, 2007), the present studies demonstrate that the cognitive effects of guilt are more far-reaching. When individuals feel guilty, they are likely to view subsequent risk-related decisions through the lens of guilt, promoting increased feelings of control and a greater tendency to take risks (Lerner \& Keltner, 2001; Schwarz \& Clore, 1983).

The present studies are the first to document an association between guilt and risk-taking, demonstrating that the experience of guilt impacts perceptions of risks, preference for risks, and the likelihood of engaging in risk-taking behavior. These findings provide an important extension of existing theory on guilt and behavior, which has focused on how guilt promotes 
moral behavior, actions aimed at reversing the effects of the guilt-inducing behavior, and/or relationship reparative actions (Lewis, 1971; Tangney \& Dearing, 2002). Here, we demonstrate that guilt promotes risk-taking and provide a broad framework for understanding why this occurs, showing that a guilt-produced enhanced sense of control lies at the root of guilt's impact on the tendency to take risks.

Our results also provide a more general explanation for why guilt may enact any type of behavior, including those treated in previous theory (e.g., Cryder, Springer, \& Morewedge, 2012): by enhancing the sense of control, guilt motivates people to act. While the present studies suggest this mechanism as a potential driver of guilt's impact on risk-taking, future studies should seek to test a causal explanation more directly, and to test this explanation for guilt's influence on other types of behavior.

Our studies also make theoretical and empirical contributions to previous theoretical treatments of guilt and the sense of control. While previous research has posited that guilt involves appraisals of personal responsibility (e.g., Smith \& Ellsworth, 1985) and action tendencies to atone for wrongdoing and make amends with those harmed (Frijda et al., 1989; Sheikh \& Janoff-Bulman, 2010; Tangney et al., 1996; Tracy \& Robins, 2006), the present work is the first to empirically demonstrate that the experience of guilt increases the sense of control. Sense of control is an important predictor of physical and mental well-being (Rodin, 1986); numerous studies, both correlational and experimental, have shown that a general sense of control leads to self-esteem, better health, and well-being (e.g., Lachman, 1986; Skinner, 1995). Our research advances prior work by showing that guilt can impact people's perceived sense of control. These findings bridge the gap between previous theory and empirical evidence, and provide a potential explanation for guilt's impact on behavior. 
More generally, our findings contribute to work examining how specific emotions impact risk perceptions, preferences, and risk-taking. Whereas certain emotions such as anger and happiness enhance risk-taking perceptions and tendencies, other emotions such as fear decrease the likelihood of risk-taking behavior (Lerner \& Keltner, 2001). Here, we show that guilt, a negative emotion associated with elevated levels of control, fits the profile of other riskenhancing emotions. This empirical contribution provides further support for a model of emotion-specific influences on risk, and also raises critical questions about the model. For example, given the present results as well as analyses demonstrating the centrality of control appraisals to decisions regarding risk (Slovic, 1987), how central are certainty appraisals to the previously observed fear and anger effects? Or might particular types of risky decisions map onto appraisals of certainty whereas others map onto appraisals of control? The present results also open the door to future investigations of other control-related emotions such as pride that may similarly impact risk perceptions, preferences, and risk-taking behavior.

While the present studies provide the first evidence of the influence of states of guilt on risk-taking and sense of control, it is important to note that they did not investigate whether trait guilt (Cohen, Wolf, Panter, \& Insko, 2011) similarly influences these constructs. Previous work on appraisal tendency has often found parallel cognitive effects of emotional traits and states on judgments (e.g., Horberg, Oveis, Keltner, \& Cohen, 2009; Lerner \& Keltner, 2001; Oveis, Horberg, \& Keltner, 2010). However, future work must test whether individuals who are dispositionally high in the tendency to experience guilt will exhibit similarly enhanced risk perceptions, risk preferences, and likelihood of engaging in risk.

We acknowledge that the way we have operationalized and tested our theory in the reported experiments was not optimal in all respects. In fact, we measured control beliefs about 
different, hard-to-control outcomes and did not measure control beliefs about the outcomes of the risky decisions that we asked participants to make. In other words, we did not explicitly measure the control beliefs of the presented choices (e.g., the outcomes of financial gambles presented).

Finally, our analyses show that sense of control as a mediator is consistent with our data, yet there could be other alternative explanations for the guilt-risky behavior link. For example, a hedonic account of guilt management could explain our findings. According to this hedonistic hypothesis, participants increase risk taking in the hopes of alleviating their feelings of guilt, to obtain a positive outcome that would counteract their guilt feelings. A negative outcome, instead, would be a deserved punishment that alleviates guilt. Future studies could test the potential for this and other alternative explanations for the effects of guilt on risk.

\section{Conclusion}

In demonstrating the impact of guilt on increased risk-taking and an enhanced sense of control, our research contributes to scholarship on guilt, to work on how emotions influence judgment, and to a better understanding of risk-taking and sense of control. By providing new insights into the parsing of negative emotions, we hope to spur future studies on the behavioral consequences of failing to live up to one's personal standards. 


\section{References}

Aarts, H., Custers, R., \& Wegner, D.M. (2005). On the inference of personal authorship: Enhancing experienced agency by priming effect information. Consciousness and Cognition, 14, 439-458.

Baumeister, R. F., Stillwell, A. M. \& Heatherton, T. F. (1994). Guilt: An interpersonal approach. Psychological Bulletin, 115, 243-267.

Blais, A-R., \& Weber, E. U. (2006). A domain-specific risk-taking (DOSPERT) scale for adult populations. Judgment and Decision Making, 1, 33-47.

Bless, H., \& Fiedler, K. (2006). Mood and the regulation of information processing and behavior. In J. P. Forgas (Ed.), Hearts and minds: Affective influences on social cognition and behavior (pp. 65-84). New York: Psychology Press.

Berndsen, M., \& Manstead, A. S. (2007). On the relationship between responsibility and guilt: Antecedent appraisal or elaborated appraisal? European Journal of Social Psychology, 37(4), 774-792.

Buhrmester, M., Kwang, T., \& Gosling, S. D. (2011). Amazon's Mechanical Turk: A new source of inexpensive, yet high-quality, data? Perspectives on Psychological Science, 6(1), 3-5.

Clore, G. L., \& Huntsinger, J. R. (2007). How emotions inform judgment and regulate thought. Trends in Cognitive Science, 11, 393-399.

Cohen, T. R., Wolf, S. T., Panter, A. T., \& Insko, C. A. (2011). Introducing the GASP scale: A new measure of guilt and shame proneness. Journal of personality and social psychology, 100(5), 947-966.

Cryder, C. Springer, S., \& Morewedge, C. M. (2012). Guilty feelings, targeted actions. Personality and Social Psychology Bulletin, 38 (5), 607-618.

Dearing, R. L., Stuewig, J., \& Tangney, J. P. (2005). On the importance of distinguishing shame 
from guilt: Relations to problematic alcohol and drug use. Addictive Behaviors, 30, $1392-1404$.

De Hooge, I. E., Nelissen, R. M. A., Breugelmans, S. M., \& Zeelenberg, M. (2011). What is moral about guilt? Acting prosocially at the disadvantage of others. Journal of Personality and Social Psychology, 100, 462-473.

Fast, N. J., Gruenfeld, D. H, Sivanathan, N., \& Galinsky, A. D. (2009). Illusory control: A generative force behind power's far reaching effects. Psychological Science, 20, 502508.

Fiedler, K. (2000). Toward an integrative account of affect and cognition using the BIAS computer algorithm. In J. P. Forgas (Ed.), Feeling and thinking: The role of affect in cognition (pp. 223-252). New York: Cambridge University Press.

Frijda, N. H., Kuipers, P., \& ter Schure, E. (1989). Relations among emotion, appraisal, and emotional action readiness. Journal of Personality and Social Psychology, 57, 212-228.

Galinsky, A. D., Magee, J. C., Gruenfeld, D. H., Whitson, J. A., \& Liljenquist, K. A. (2008). Power reduces the press of the situation: Implications for creativity, conformity, and dissonance. Journal of Personality and Social Psychology, 95, 1450-1466.

Griskevicius, V., Tybur, J. M., Delton, A. W., \& Robertson, T. E. (2011). The influence of mortality and socioeconomic status on risk and delayed rewards: A life history theory approach. Journal of Personality and Social Psychology, 100, 1015-1026.

Haggard, P. \& Tsakiris, M. (2009). The experience of agency: Feelings, judgments, and responsibility. Current Directions in Psychological Science, 18, 242-246.

Han, S., Lerner, J. S., \& Keltner, D. (2007). Feelings and consumer decision making: The appraisal-tendency framework. Journal of Consumer Psychology, 17, 158-168. 
Hanoch, Y., Johnson, J.G., \& Wilke, A. (2006). Domain specificity in experimental measures and participant recruitment. Psychological Science, 17, 300-304.

Horberg, E. J., Oveis, C., \& Keltner, D. (2011). Emotions as moral amplifiers: An appraisal tendency approach to the influences of distinct emotions upon moral judgment. Emotion Review, 3, 237-244.

Horberg, E. J., Oveis, C., Keltner, D., \& Cohen, A. B. (2009). Disgust and the moralization of purity. Journal of Personality and Social Psychology, 97, 963-976.

Izard, C. E. (1977). Human emotions. New York: Plenum Press.

Keltner, D., Horberg, E. J., \& Oveis, C. (2006). Emotions as moral intuitions. In J. P. Forgas (Ed.), Affect in social thinking and behavior (pp. 161-175). New York: Psychology Press.

Lachman, M. E. (1986). Locus of control and aging research: A case for multidimensional and domain-specific assessment. Psychology and Aging, 1, 34-40.

Langer, E. (1975). The illusion of control. Journal of Personality and Social Psychology, 32, $311-328$.

Lazarus, R. (1991). Emotion and Adaptation. New York: Oxford University Press.

Lerner, J. S., \& Keltner, D. (2001). Fear, anger, and risk. Journal of Personality and Social Psychology, 81, 146-159.

Lewis, H. B. (1971). Shame and guilt in neurosis. New York: International University Press.

Lewis, M. (2008). Self-conscious emotions: Embarrassment, pride, shame, and guilt. In M. Lewis, \& J. M. Haviland-Jones (Eds.), Handbook of emotions (pp. 742-757). New York: Guilford Press.

Lindsay-Hartz, J. (1984). Contrasting experiences of shame and guilt. American Behavioral Scientist, 27, 689-704. 
Lindsay-Hartz, J. L., de Rivera, J., \& Mascolo, M. F. (1995). Differentiating guilt and shame and their effects on motivation. In J. P. Tangney \& K. W. Fisher (Eds.), Self-conscious emotions: The psychology of shame, guilt, embarrassment and pride (pp. 274-300). New York, NY: Guilford Press.

Linser, K. \& Goschke, T. (2007). Unconscious modulation of the conscious experience of control. Cognition, 104, 459-475.

Ortony, A., Clore, G. L., \& Collins, A. (1988). The cognitive structure of emotions. New York, NY: Cambridge University Press.

Oveis, C., Horberg, E. J., \& Keltner, D. (2010). Compassion, pride, and social intuitions of selfother similarity. Journal of Personality and Social Psychology, 98, 618-630.

Preacher, K. J., \& Hayes, A. F. (2004). SPSS and SAS procedures for estimating indirect effects in simple mediation models. Behavior Research Methods, Instruments, \& Computers, 36, 717-731.

Scheier, M.F., Carver, C.S., \& Bridges, M.W. (1994). Distinguishing optimism from neuroticism (and trait anxiety, self-mastery, and self-esteem): A reevaluation of the Life Orientation Test. Journal of Personality and Social Psychology, 67, 1063-1078.

Schwarz, N., \& Clore, G. L. (1983). Mood, misattribution, and judgments of well-being: Informative and directive functions of affective states. Journal of Personality and Social Psychology, 45, 513-523.

Siemer, M. (2001). Mood-specific effects on appraisal and emotion judgements. Cognition \& Emotion, 15(4), 453-485.

Sheikh, S., \& Janoff-Bulman, R. (2010). The "shoulds" and "should nots" of moral emotions: A self-regulatory perspective on shame and guilt. Personality and Social Psychology 
Bulletin, 36, 213-224.

Skinner, E. A. (1996). A guide to constructs of control. Journal of Personality and Social Psychology, 71, 549-570.

Slovic, P. (1987). Perception of risk. Science, 236, 280-285.

Smith, C. A., \& Ellsworth, P. C. (1985). Patterns of cognitive appraisal in emotion. Journal of Personality and Social Psychology, 48, 813-838.

Smith, C. A., \& Lazarus, R. S. (1993). Appraisal components, core relational themes, and the emotions. Cognition \& Emotion, 7, 233-269.

Tangney, J. P., \& Dearing, R. L. (2002). Shame and guilt. New York, NY: Guilford Press.

Tangney, J. P., Miller, R. S., Flicker, L., \& Barlow, D. H. (1996). Are shame, guilt, and embarrassment distinct emotions? Journal of Personality and Social Psychology, 70, $1256-1269$.

Tracy, J. L., \& Robins, R. W. (2006). Appraisal antecedents of shame and guilt: Support for a theoretical model. Personality and Social Psychology Bulletin, 32, 1339-1351.

Watson, D., Clark, L.A., \& Tellegen, A. (1988). Development and validation of brief measures of positive and negative affect: The PANAS scales. Journal of Personality and Social Psychology, 54, 1063-1070.

Winterich, K. P., Han, S., \& Lerner, J. S. (2010). Now that I'm sad, it's hard to be mad: The role of cognitive appraisals in emotional blunting. Personality and Social Psychology Bulletin, 36(11), 1467-1483. 
Table 1. Descriptive statistics and correlations for Study 6

\begin{tabular}{lcccccccccc}
\hline \multicolumn{1}{c}{ Variable } & Mean & s.d. & $\mathbf{1}$ & $\mathbf{2}$ & $\mathbf{3}$ & $\mathbf{4}$ & $\mathbf{5}$ & $\mathbf{6}$ & $\mathbf{7}$ & $\mathbf{8}$ \\
\hline 1. Risk-taking & 1.34 & 1.27 & & & & & & & & \\
2. Illusion of control & 2.13 & 1.15 & $.20^{*}$ & & & & & & \\
3. Control & 2.77 & 1.27 & $.15 \%$ & $.21^{*}$ & & & & & & \\
4. Uncertainty & 2.77 & 1.26 & $.19 *$ & .13 & $.31^{* * *}$ & & & & & \\
5. Responsibility & 5.33 & 1.29 & -.05 & $-.23^{* *}$ & $-.66^{* * *}$ & $-.25^{* *}$ & & & & \\
6. Pleasantness & 4.20 & 1.95 & -.02 & .10 & -.01 & $-.19^{*}$ & .02 & & & \\
7. Exchange & 3.21 & 2.32 & .12 & $.23^{* *}$ & .07 & $.44^{* * *}$ & .07 & $-.23^{* *}$ & & \\
8. Assimilation & 3.35 & 1.19 & .13 & $.21^{*}$ & $.29^{* *}$ & $.26^{* *}$ & $-.21^{*}$ & -.14 & $.42^{* * *}$ \\
9. Approach & 4.37 & 1.56 & -.11 & .10 & -.14 & $-.36^{* * *}$ & .05 & $.26^{* *}$ & $-.38^{* * *}-.30^{* * *}$ \\
\hline$N=136$. & & & & & & & & &
\end{tabular}

